\begin{tabular}{|l|l|}
\hline Postprint Version & Final draft post-refereeing \\
\hline Journal website & $\underline{\text { http://informahealthcare.com/ipo }}$ \\
\hline Pubmed link & $\underline{\text { http://www.ncbi.nlm.nih.gov/pubmed/20184505 }}$ \\
\hline DOI & $\underline{10.3109 / 17477160903449986}$ \\
\hline
\end{tabular}

\title{
Prevalence of overweight and underweight in public and private schools in the Seychelles
}

\author{
Pascal Bovet ${ }^{1,2}$, Arnaud Chiolero², George Madeleine ${ }^{1}$, Fred Paccaud ${ }^{2}$ \\ ${ }^{1}$ Ministry of Health and Social Development, Victoria, Republic of Seychelles \\ ${ }^{2}$ Institute of Social and Preventive Medicine (IUMSP), University Hospital Center and \\ University of Lausanne, 1005 Lausanne, Switzerland
}

\section{Address for correspondence:}

Dr Pascal Bovet

Ministry of Health and Social Development

Section for Non-Communicable Diseases

PO Box 52

Victoria, Republic of Seychelles

Tel: +248388000

Email: bovet.pascal@gmail.com or pascal.bovet@chuv.ch

\begin{abstract}
Objective: We compared the prevalence of body weight categories between public and private schools in the Seychelles, a rapidly developing small island state in the African region.

Methods: In 2004-2006, weight and height were measured and self-reported information on physical activity collected in children of three selected grades in all schools in the country. Overweight, obesity and thinness were defined according to standard criteria.

Results: Based on 8462 students ( 377 in private schools), the prevalence of overweight (including obesity) was markedly higher in private than public schools (boys: $37 \%$ [95\% $\mathrm{Cl}: 31-44]$ vs. $15 \%$ [14-16]; girls: $33 \%$ [26-41] vs. $20 \%$ [19-22]). The prevalence of thinness grade 1 was lower in private than public schools (boys: $9 \%$ [5-13] vs. 20\% [1921]; girls: $13 \%$ [8-18] vs. $19 \%$ [18-20]). Patterns of physical activity are also reported.

Conclusions: Our findings suggest that school type may be a useful indicator for assessing the association between socio-economic status and overweight in children and that overweight affects more often wealthy children than others in developing countries.
\end{abstract}

Keywords: overweight, obesity, underweight, thinness, physical activity, socio-economic status, children, adolescents, Seychelles, Africa 


\section{Introduction}

The prevalence of obesity in children is increasing in most countries [1]. However, few studies have assessed the association between obesity in children and socio-economic status (SES) in developing countries. None of the 45 studies included in a recent review about this issue [2] were from a low or middle income country.

Frequently used indicators to assess SES in children include parental education, parental occupation, indices of family income, and indicators of neighbourhood [2]. Interestingly, school type - private vs. public- is rarely used as a marker of SES, and this indicator was not reported in a glossary of SES indicators [3-4].

In this study, we compared the prevalences of overweight, obesity and underweight between students attending public vs. private schools in the Seychelles islands, a rapidly developing country in the African region.

\section{Methods}

The Republic of Seychelles is an archipelago located in the Indian Ocean, east of Kenya and north of Mauritius. Approximately $90 \%$ of the population lives in the main island (Mahé, main town: Victoria). The majority of the population is of African descent.

Nearly $100 \%$ of all children attend school up to the $10^{\text {th }}$ grade with approximately $96 \%$ in public schools. Tuitions for attending private school in the Seychelles reach US $\$ 4000$ 5000 per student and per year, which is approximately equivalent to a one-year salary of a labourer or a junior secretary.

This study uses data from an ongoing routine surveillance program in which school nurses screen every year all students of kindergarten, $4^{\text {th }}, 7^{\text {th }}$ and $10^{\text {th }}$ levels in all public and private schools, except for one private school, as previously described $[5,6]$, The program is conducted under the auspices of the Ministry of Health and the Ministry of Education, following technical and ethical reviews. Parents were requested to provide a signed consent for the participation of their children in the screening program and students participated on a voluntary basis.

We included data from all the schools that have both primary and secondary classes. We limited the study period to a three-year period (2004-2006) to maximize the sample size while ensuring that the participants could not have been screened more than once. We excluded data from kindergarten as lifestyle variables were not collected for this grade.

Weight and height were measured using precision scales (Seca 870, Seca, Hamburg) and fixed stadiometers (Seca 208). Body mass index (BMI) was calculated $\left(\mathrm{kg} / \mathrm{m}^{2}\right.$ ). Underweight, overweight, and obesity were defined using standard sex- and -agespecific BMI cut-off values $[7,8]$. Unless specified otherwise, the word "overweight" also includes obesity in this paper. Students were also submitted to a short face-to-face structured questionnaire including questions on their average daily walking time to and from school and leisure physical activity outside of school.

We calculated the prevalences and 95\% confidence intervals of body weight and physical activity categories according to school location and school type. The association between overweight and selected variables was examined using multivariate logistic regression. Statistical analyses were performed with Stata 8.2. 


\section{Results}

This study included 8462 students (overall participation rate of $87.9 \%$, with no substantial differences between schools). Mean age (SD) of the students was $9.2(0.4)$, $12.6(0.4)$ and $15.3(0.4)$ years in the $4^{\text {th }}, 7^{\text {th }}$ and $10^{\text {th }}$ grades, respectively.

The prevalence of overweight was not substantially different between public schools, but the prevalence was markedly higher in private schools than in public schools (Table). The prevalence of overweight was higher in girls than in boys in public schools but higher in boys than in girls in private schools. The prevalence of thinness of grade 1 (corresponding to $\mathrm{BMI}=18.5$ in adults) and grade 2 (corresponding to $\mathrm{BMI}=17.0$ in adults) was lower in private schools than in public schools. The overall prevalence of grade 3 thinness (corresponding to $\mathrm{BMI}=16.0$ in adults) was $2.2 \%$ in boys and $1.4 \%$ in girls, with little difference between public schools and private schools. The differences in thinness and in overweight in private schools vs. public schools suggest that the entire $\mathrm{BMI}$ distribution was shifted towards higher values in the former than the latter.

Walking less than 10 minutes per day was reported by nearly all the students in private schools but by only one third of the students in public schools. Regular physical activity at leisure time was reported more often by boys than girls (in all schools) and more often by students of private schools than public schools.

Multivariate analysis, adjusting for sex and age, showed that obesity was i) associated with private school (OR [95\% Cl]: 3.10 [2.18-4.40]); ii) not associated with walking time; and iii) inversely associated with physical activity at leisure time (OR: 0.74 [0.590.93 ] for physical activity on 1-2 days per week vs. <1 day per week, and 0.58 [0.450.73 ] for physical activity on $\geq 3$ days per week vs. $<1$ day per week).

\section{Discussion}

We found that the prevalence of overweight was approximately two times higher, and the prevalence of thinness two times lower, in students in private schools compared to students in public schools. The patterns of physical activity differed according to school type: walking was reported more often by students in public schools while physical exercise at leisure time was reported more often by students in private schools.

To our knowledge, only one other study used school type as a marker of SES, with similar results to ours [9]. The association between school type (private/public) and overweight may be underestimated as students from many families of high SES also attend public schools. Furthermore, students in public schools ( $96 \%$ of all students) do not occupy a specific SES category but, instead, they represent largely different socioeconomic positions, from highest to lowest. From a construct perspective, the category of SES defined by attending a private school implies a high salary of the parents; hence the SES indicator largely reflects substantial wealth of a student's family. However, a number of not so wealthy but highly educated parents may make special efforts to send their children to private schools. Overall, the validity of a SES construct defined by attending a private school vs. a public school may vary across different populations. Nonewithstanding these caveats, our results suggest that contrasting the prevalences of body weight categories between private schools vs. public schools can be a potentially simple strategy for assessing the association between SES and overweight in children and adolescents. Noticeably, this strategy enables to avoid asking the students or their parents about parents' education, occupation or salary, which may be both sensitive and unreliable $[3,4]$.

The higher prevalence of overweight in girls than in boys and the SES patterning of overweight mirror what is observed among adults in the Seychelles [10]. Similar 
associations have been found in other low or middle income countries both in adults [11] and in children $[12,13]$. While the association between overweight and SES may depend on which SES indicator is used $[3,11,14]$, positive associations are often found with income and material possessions, particularly in medium-income countries, while negative associations are often found with education, particularly in women from highincome countries [11].

Sobal suggested that SES components may operate via different pathways: education can influence knowledge and beliefs; lifestyle and peer values can be shared by occupation categories; and income can drive access to resources [15]. Students of wealthy families can afford to buy more food and soft drinks, including at the tuck shops in the school premises, which may fuel a continuously positive energy balance. Furthermore, children share, at home, the same diet and lifestyles as their parents. These factors are consistent with social patterning of body weight developing early in the life course.

Low walking time by students in private schools is likely related to the fact that they are often driven by car to school by their parents. The higher frequency of physical activity at leisure time among students in private schools than in public schools is consistent with emphasis on sports given in the former as well as with increased opportunities (affordability, access) for children of wealthy families to participate in sports at leisure time. Our finding that the prevalence of obesity is associated (inversely) with physical activity at leisure time, but not with walking time, is consistent with other studies $[16,17]$. Of note, our findings related to this association largely rely on data from students in public schools (i.e. $96 \%$ of all students).

The study has a few limitations. Some obese children may have declined to participate in the school screening by fear of stigmatization. However, such a bias is unlikely to be socially determined and is likely to occur similarly in all schools. Self-reported physical activity has been grossly evaluated by two questions and may be unreliable. On the other hand, the strengths of this study include the population-based study design; a large sample size; measurement of anthropometric variables with standardized instruments; good participation rates; and high school enrolment.

In conclusion, our findings suggest that school type may be a useful indicator for assessing the association between socio-economic status and overweight in children and adolescents. Furthermore, the paper shows that overweight affects more often wealthy children than others in the Seychelles; this illustrates one of the paradigms of the epidemiological transition according to which noncommunicable diseases and their risk factors enter into a population via persons of the highest SES category.

Acknowledgments: We are grateful to the programme managers and all the nurses of the school health programme for collecting the data. We also thank the Ministry of Health and Social Development and the Ministry of Education for support to the programme.

Conflict of interest: none declared 


\section{References}

1) Lobstein T, Baur L, Uauy R; IASO International Obesity Task Force. Obesity in children and young people: a crisis in public health. Obes Rev. 2004;5 Suppl 1:4104.

2) Shrewsbury $V$, Wardle J. Socioeconomic status and adiposity in childhood: a systematic review of cross-sectional studies 1990-2005. Obesity. 2008; 16:275-84.

3) Galobardes B, Shaw M, Lawlor DA, Lynch JW, Davey Smith G. Indicators of socioeconomic position (part 1). J Epidemiol Community Health. 2006; 60: 7-12.

4) Galobardes B, Shaw M, Lawlor DA, Lynch JW, Davey Smith G. Indicators of socioeconomic position (part 2). J Epidemiol Community Health. 2006; 60: 95-101.

5) Bovet P, Chiolero A, Madeleine G, Gedeon A, Stettler N. Marked increase in the prevalence of obesity in children of the Seychelles (Indian Ocean), 1998-2004. Int J Ped Obes. 2006; 2:120-28.

6) Chiolero A, Paradis G, Madeleine G, Paccaud F, Bovet P. Discordant secular trends in elevated blood pressure and obesity in children and adolescents. Circulation. 2009; 119: 558-65.

7) Cole TJ, Bellizzi MC, Flegal KM, Dietz WH. Establishing a standard definition for child overweight and obesity worldwide: international survey. BMJ . 2000;320:1240-43.

8) Cole TJ, Flegal KM, Nicholls D, Jackson AA. Body mass index cut offs to define thinness in children and adolescents: international survey. BMJ $2007 \mathrm{~J} \mathrm{ul}$ 28; 335(7612): 194.

9) Groeneveld IF, Solomons NW, Doak CM. Determination of central body fat by measuring natural waist and umbilical abdominal circumference in Guatemalan schoolchildren. Int J Pediatr Obes. 2007;2:114-21.

10) Bovet $P$, Chiolero $A$, Shamlaye $C$, Paccaud F. Prevalence of overweight in the Seychelles: 15 year trends and association with socio-economic status. Obes Rev. 2008; 9: 511-17.

11) McLaren L. Socioeconomic status and obesity. Epidemiol Rev. 2007; 29:29-48.

12) Wang Y. Cross-national comparison of childhood obesity: the epidemic and the relationship between obesity and socioeconomic status. Int J Epidemiol. 2001; 30: 1129-36.

13) Srihari G, Eilander A, Muthayya S, Kurpad AV, Seshadri S. Nutritional status of affluent Indian school children: what and how much do we know? Indian Pediatr. 2007; 44:204-13.

14) Ball K, Crawford D. Socioeconomic status and weight change in adults: a review. Soc Sci Med. 2005; 60: 1987-2010.

15) Sobal J. Obesity and socioeconomic status: a framework for examining relationships between physical and social variables. Med Anthropol. 1991;13:231-47.

16) Faulkner GEJ, Buliung RN, Flora PK, Fusco C. Active school transport, physical activity levels and body weight of children and youth: a systematic review. Prev Med 2009; 48, 3-8.

17) Riddoch CJ, Leary SD, Ness AR, Blair SN, Deere K. Prospective associations between objective measures of physical activity and fat mass in 12-14 year old children: the Avon Longitudinal Study of Parents and Children (ALSPAC). BMJ (in press). 
Table. Prevalence of categories of body weight and physical activity in school children according to school type, school location and sex

\begin{tabular}{|c|c|c|c|c|c|c|c|c|c|c|c|c|c|c|}
\hline & \multicolumn{8}{|c|}{ Public schools } & & & \multirow{2}{*}{\multicolumn{2}{|c|}{$\begin{array}{c}\text { Private schools } \\
\text { Victoria }\end{array}$}} & \multirow{2}{*}{\multicolumn{2}{|c|}{ Total }} \\
\hline & \multicolumn{2}{|c|}{ Victoria or nearby } & \multicolumn{2}{|c|}{ 5-15 km from Victoria } & \multicolumn{2}{|c|}{$>20 \mathrm{~km}$ from Victoria } & \multicolumn{2}{|c|}{ Other islands } & \multicolumn{2}{|c|}{ All public schools } & & & & \\
\hline & Boys & Girls & Boys & Girls & Boys & Girls & Boys & Girls & Boys & Girls & Boys & Girls & Boys & Girls \\
\hline $\mathrm{n}$ & 1131 & 1181 & 1021 & 1046 & 1271 & 1286 & 610 & 539 & 4033 & 4052 & 206 & 171 & 4239 & 4223 \\
\hline \multicolumn{15}{|l|}{ Excess body weight } \\
\hline \multirow[t]{2}{*}{ Overweight or obese (\%) } & 14.9 & 19.7 & 16.4 & 21.1 & 13.9 & 20.4 & 16.3 & 20.8 & 15.2 & 20.4 & 37.4 & 33.3 & 16.3 & 21.0 \\
\hline & $13-17$ & $17-22$ & $14-19$ & $19-24$ & $12-16$ & $18-23$ & $13-19$ & $17-24$ & $14-16$ & $19-23$ & $31-44$ & $26-40$ & $15-17$ & $20-22$ \\
\hline \multirow[t]{2}{*}{ Obese (\%) } & 5.0 & 7.8 & 5.5 & 5.8 & 4.0 & 6.4 & 4.9 & 7.6 & 4.8 & 6.8 & 18.0 & 11.2 & 5.4 & 7.0 \\
\hline & $3.7-6.2$ & $6.2-9.3$ & $4.1-6.9$ & $4.4-7.2$ & $2.9-5.1$ & $5.0-7.7$ & $3.2-6.6$ & $5.4-9.8$ & $4.1-5.4$ & $6.0-7.6$ & $13-23$ & $6.4-16$ & $4.7-6.1$ & $6.2-7.8$ \\
\hline \multicolumn{15}{|l|}{ Underweight } \\
\hline \multirow[t]{2}{*}{ Thinness grade 1 (\%) } & 21.0 & 17.5 & 19.3 & 20.6 & 20.4 & 18.7 & 19.8 & 17.2 & 20.1 & 18.8 & 8.7 & 12.8 & 19.7 & 18.6 \\
\hline & $19-23$ & $15-20$ & $17-22$ & $18-23$ & $18-23$ & $17-21$ & $17-23$ & $14-20$ & $19-21$ & $18-20$ & $4.8-13$ & $7.8-18$ & $19-21$ & $18-20$ \\
\hline \multirow[t]{2}{*}{ Thinness grade 2 (\%) } & 5.6 & 5.8 & 4.7 & 5.9 & 6.1 & 5.8 & 4.8 & 5.2 & 5.3 & 5.7 & 1.9 & 1.7 & 5.2 & 5.6 \\
\hline & $4.2-6.9$ & $4.5-7.2$ & $3.4-6.0$ & $4.5-7.4$ & 4.8-7.4 & $4.5-7.1$ & 3.1-6.5 & 3.3-7.1 & $4.7-5.8$ & $5.1-6.3$ & $0-3.8$ & $0-3.7$ & $4.6-5.7$ & $5.0-6.2$ \\
\hline \multicolumn{15}{|l|}{ Walking to/from school } \\
\hline \multirow[t]{2}{*}{$<10 \min /$ day $(\%)$} & 23 & 20 & 32 & 23 & 44 & 39 & 43 & 40 & 35 & 30 & 96 & 94 & 38 & 32 \\
\hline & $20-25$ & $18-22$ & $29-35$ & $21-26$ & $41-46$ & $37-42$ & $39-47$ & $36-45$ & $33-36$ & $28-31$ & $93-99$ & $90-98$ & $36-39$ & $31-34$ \\
\hline \multirow[t]{2}{*}{ 10-30 min/day (\%) } & 49 & 47 & 48 & 52 & 37 & 39 & 52 & 54 & 45 & 46 & 4 & 6 & 43 & 45 \\
\hline & $46-52$ & $44-50$ & $45-52$ & $49-55$ & $34-39$ & $36-41$ & $47-56$ & $49-58$ & $43-46$ & $45-48$ & $1-6$ & $2-10$ & $42-45$ & $43-46$ \\
\hline \multirow[t]{2}{*}{ >30 min/day (\%) } & 28 & 33 & 20 & 25 & 19.5 & 22 & 5 & 6 & 20 & 24 & 0 & 0 & 19 & 23 \\
\hline & $26-31$ & $30-36$ & $18-23$ & $22-27$ & $17-22$ & $20-24$ & $3-7$ & $4-9$ & $19-22$ & $23-25$ & - & - & $18-21$ & $22-24$ \\
\hline \multicolumn{15}{|c|}{ Physical activity during leisure time } \\
\hline \multirow[t]{2}{*}{$<1$ time/week $(\%)$} & 22 & 37 & 36 & 53 & 12 & 20 & 19 & 35 & 22 & 35 & 5 & 18 & 21 & 35 \\
\hline & $20-25$ & $35-40$ & $33-39$ & $50-56$ & $10-14$ & $17-22$ & $16-22$ & $31-40$ & $21-23$ & $34-37$ & $2-8$ & $12-23$ & $20-22$ & $33-36$ \\
\hline \multirow[t]{2}{*}{ 1-2 times/week (\%) } & 30 & 42 & 31 & 25 & 31 & 48 & 38 & 37 & 32 & 39 & 20 & 26 & 31.2 & 38 \\
\hline & $27-33$ & $38-44$ & $28-34$ & $23-28$ & $27-34$ & $46-51$ & $34-42$ & $33-41$ & $30-33$ & $38-41$ & $14-25$ & $19-32$ & $30-33$ & $37-40$ \\
\hline \multirow[t]{2}{*}{$\geq 3$ times/week (\%) } & 48 & 21 & 33 & 22 & 57 & 32 & 43 & 28 & 46 & 26 & 75 & 56 & 47.8 & 27 \\
\hline & $45-51$ & $19-23$ & $31-36$ & $19-25$ & $54-59$ & $29-35$ & $39-47$ & $24-32$ & $45-48$ & $24-27$ & $69-81$ & $49-64$ & $46-49$ & $26-28$ \\
\hline
\end{tabular}

Values are percentage and 95\% confidence interval. 